\title{
Animais demais... os xerimbabos no espaço doméstico matis (Amazonas)
}

Animals galore... pets in Matis domestic space (Amazonas)

\section{Philippe Erikson}

Tradutor. Carlos Emanuel Sautchuk e José Pimenta

\section{(2) OpenEdition Journals}

\section{Edição electrónica}

URL: http://journals.openedition.org/aa/110

DOI: $10.4000 /$ aa. 110

ISSN: 2357-738X

\section{Editora}

Programa de Pós-Graduação em Antropologia Social (UnB)

\section{Edição impressa}

Data de publição: 1 dezembro 2012

Paginação: 15-32

ISSN: 0102-4302

\section{Refêrencia eletrónica}

Philippe Erikson, «Animais demais... os xerimbabos no espaço doméstico matis (Amazonas)», Anuário Antropológico [Online], v.37 n.2 | 2012, posto online no dia 18 outubro 2013, consultado o 28 abril 2021. URL: http://journals.openedition.org/aa/110 ; DOI: https://doi.org/10.4000/aa.110

\section{(c) (i) (9)}

Anuário Antropológico is licensed under a Creative Commons Atribuição-Uso Não-Comercial-Proibição de realização de Obras Derivadas 4.0 International. 


\section{Animais demais... os xerimbabos no espaço doméstico matis (Amazonas)}

Philippe Erikson

Université Paris Ouest Nanterre

Tradução: Carlos Emanuel Sautchuk e José Pimenta

"Animais demais": o título deste artigo é, em primeiro lugar, uma alusão ao que se poderia chamar de uma onipresença dos animais não somente no imaginário e na alimentação, mas também no espaço doméstico das populações indígenas da Amazônia. Concretamente, os animais estão em todos os lugares - nas malocas, nas roças, nos locais de banho e até sobre a cabeça das crianças. "Animais demais", como não deixaram de notar os primeiros observadores, estupefatos com a superabundância e a importância conferida aos animais de companhia nas aldeias que eles encontravam.

Vejamos, por exemplo, como Jules Crevaux (1987 [1879]:32), não sem humor, descreveu sua chegada entre os ameríndios da Guiana Francesa: "Jacamins, jacus, araras vêm esvoaçar em torno de mim; uma pequena onça amansada se lança de uma vez sobre minhas costas e rasga minha jaqueta. Namaoli faz um gesto e todos esses animais batem em retirada...”. Aproximadamente na mesma época, o general Couto de Magalhães escreveu em sua obra O Selvagem (1876):

Quem visita uma aldeia selvagem visita quase um museu vivo de zoologia da região onde está a aldeia; araras, papagaios de todos os tamanhos e cores, macacos de diversas espécies, porcos, quatis, mutuns, veados, avestruzes e até sucurijus, jiboias e jacarés. [...] O cherimbabo do índio (o animal que ele cria) é quase uma pessoa de sua família (apud Calavia Saez, 2010).

Apesar de seu tom algo anacrônico, tais observações não perderam nada de sua pertinência. Em todo caso, elas poderiam se aplicar à situação dos Matis, tal como tive o privilégio de encontrá-los no início dos anos 1980, quando de minhas primeiras pesquisas de campo realizadas sob o patrocínio de Julio Cezar Melatti (da Universidade de Brasilía) e sob a batuta de Patrick Menget. Os ensinamentos deste último, na Universidade Paris X-Nanterre, haviam me sensibilizado para a 
questão da catividade no universo amazônico, de tal maneira que não me restava senão transportá-la ao registro das relações homem-animal (Erikson, 1987).

"Animais demais" é igualmente uma piscada de olhos a um texto recente, intitulado "donos demais", no qual Carlos Fausto (2008) atualiza a questão essencial do controle social, tal como ele é vivido e conceitualizado na Amazônia indígena. Este é precisamente o segundo eixo em torno do qual é estruturado o texto abaixo (cuja primeira versão remonta a 1988), que parte de uma reflexão sobre a inserção de animais de estimação no espaço doméstico matis, para tentar estabelecer uma relação entre esta prática e as representações que a sustentam. Em outras palavras, é um texto que se interessa pelas relações simbólicas complexas que os ameríndios estabelecem entre os lugares de que se apropriaram (seu habitat) e os seres vivos (animais, vegetais e humanos) que ali se encontram ou transitam. Em tal contexto, é sem dúvida a figura do "dono" e as noções de "mestria" (sobre os indivíduos, mas também sobre os espaços) que são mobilizadas para caracterizar a relação dos humanos com os animais. Tanto aqueles cativos quanto os semilibertos, ou mesmo em simbiose perfeita, quer dizer, quando eles são tratados em pé de igualdade com seus novos "parentes" humanos. Um dos argumentos principais deste texto, como da maior parte daqueles que escrevi sobre esta temática, é precisamente que a relação homem-animal só pode ser interpretada considerando-se a situação de rivalidade (sobretudo com os espíritos-donos da caça) que conduz a inserção dos animais no espaço doméstico dos homens.

Ainda que elas tenham sido remanejadas tendo em vista esta nova publicação, as ideias que seguem não são totalmente inéditas. Uma primeira versão foi publicada no final dos anos 1980, numa revista francesa de difusão restrita (Erikson, 1988). Sem dúvida, o texto envelheceu, mas parece que é útil retomá-lo hoje por duas razões essenciais. Em primeiro lugar, porque ele é antes de tudo baseado na etnografia que, longe de se degradar, tende a amadurecer com a idade, o que justifica assim uma nova versão em português, que tem, ademais, o mérito de ampliar a audiência do texto. Em segundo lugar, porque as temáticas outrora abordadas parecem ter conhecido recentemente uma retomada de interesse que justifica talvez que ele seja retirado da sombra. Após a aparição de meus primeiros trabalhos sobre a relação entre homem e animal na Amazônia (Erikson, n.d. [1983]), o tema se enriqueceu e se sofisticou. Teses foram consagradas ao assunto (Cormier, 2003a, 2003b; Vander Velden, 2010, 2011), novas hipóteses foram formuladas (Texeira Pinto, 1997; Descola, 1998a, 1998 b) e novos dados produzidos (Dal Poz, 1993; Villar, 2005; Dienst \& Fleck, 2009; Koster, 2009), tudo chamando ao debate.

A questão da relação homem-animal é incontestavelmente o que me levou no início a trabalhar na Amazônia. Porém, um quarto de século após meus 
primeiros passos no campo, é forçoso constatar que apenas uma ínfima parte de minha produção acadêmica tratou deste tema, e numa ótica mais comparativa do que descritiva. Em outras palavras, de uma maneira claramente mais voltada à síntese da literatura existente do que à análise de dados etnográficos originais. Como toda carreira de etnólogo, a minha oscilou com frequência entre os dois polos opostos que são o campo e a teoria. Entretanto, o essencial de meu trabalho empírico, mesmo aquele resultante de meu próprio trabalho de campo entre os Matis, incitou-me sobretudo a falar de cosmologia, de rituais, de ornamentos corporais e de parentesco, mais do que de animais... As reflexões abaixo constituem uma das raras exceções a esta regra e eu me sinto tão mais feliz de vê-las... reaparecerem hoje neste número especial do Anuário Antropológico.

$* * *$

Os Matis vivem em uma grande casa comum chamada shobo. Enquanto espaço coletivo, o shobo não pertence ao domínio público: os critérios de pertencimento e os protocolos de entrada são extremamente restritivos, ainda que sua codificação seja apenas tácita na maior parte dos casos. Além disso, cada coisa e cada pessoa dispõem de um lugar tradicional em um shobo: os troféus ficam acima das entradas laterais, as zarabatanas entre os pilares centrais, as grandes peças de cerâmica nas extremidades, os arcos nas paredes, as redes de dormir em compartimentos especiais, os dos homens sobre os das mulheres, os bancos no círculo central... Aqui, tudo é ordem e tradição, composição, harmonia e organização. Os detalhes e as proporções podem variar de um shobo para outro, mas o esquema diretor permanece sempre idêntico.

Além de seus ocupantes humanos, um shobo abriga sempre alguns animais domésticos (cães e galinhas, de introdução recente), alguns quelônios destinados a um consumo diferido (reserva alimentar estocada in vivo) e, sobretudo, incontáveis animais familiares, cuja gama varia tanto quanto o leque alimentar: pássaros, roedores, preguiças e uma quantidade impressionante de pequenos macacos, que seus donos portam quase sempre sobre a cabeça (ver a lista detalhada na tabela 1$){ }^{1}$

Como estes animais familiarizados inserem-se no espaço eminentemente civilizado do shobo? Se, num primeiro olhar, os xerimbabos estão por todos os lados, literalmente invadindo a casa, não haveria alguma ordem por trás disto? Os xerimbabos não são posicionados como o resto, com uma localização bem definida e fisicamente circunscrita na casa dos homens?

Tais questões mostram-se ainda mais relevantes quando se leva em consideração que o espaço humano é concebido pelos Matis justamente numa relação 
com o espaço animal. Ao invés de simplesmente oporem "cultura humana" e "natureza animal”, os Matis consideram que tudo é cultura, inclusive a floresta que, acredita-se, foi plantada pelos animais ou espíritos que nela vivem e dela se alimentam. Portanto, supõe-se que cada parcela do universo tem um único dono, em decorrência do que há um grande cuidado em marcar a distinção entre os locais ocupados pelos homens (habitações, roças, caminhos) e os demais. Infeliz daquele que, incapaz de distinguir o traçado de um antigo caminho encoberto pela vegetação secundária, se aventura a urinar ali: uma vez sob influência, uma área assim deve permanecer. Criar um enclave socializado no meio da floresta significa, desta forma, tomar posse de um lugar antigamente dominado por animais ou entidades sobrenaturais.

Assim, o espaço desmatado pelos humanos foi conquistado não contra uma "natureza" abstrata, mas contra antigos ocupantes agora despossuídos. Os lugares dos homens se definem, portanto, em relação aos dos animais, mas pautados na exclusividade. Justamente por isto, é um tanto paradoxal reintroduzir numa área recentemente apropriada pelos humanos aqueles mesmos (os animais) que a dominavam antes e dela foram expulsos. Compreende-se facilmente que cada coisa disponha de um lugar predefinido num shobo, mas parece, por outro lado, dificilmente concebível que os animais tenham aí o seu lugar.

O problema lógico apresentado pelo deslocamento de animais destinados a se tornarem xerimbabos parece de alguma maneira contido na definição do termo wiwa, que designa os seres familiarizados. O componente essencial desta noção - que se aplica igualmente aos vegetais - não é tanto a ideia de controle sobre a reprodução (as plantas cultivadas não são wiwa), mas a ideia de se responsabilizar por indivíduos deslocados de seus locais de origem para entrarem na esfera de influência dos humanos. A muda de um cipó estimulante (tachik) torna-se, por exemplo, tachik wiwa após ter sido transplantada para a proximidade de uma habitação, num local que facilitará sua colheita posterior. De certa maneira, pode-se dizer que os wiwa animais foram, eles também, artificialmente "implantados" num local controlado pelos humanos, o que confere a eles um estatuto altamente ambíguo, que Behrens (1983:233) observou a propósito da categoria dos ina (equivalente de wiwa entre os Shipibo, também de língua pano): "Ina [...] é uma categoria de transição [...] i.e. [...] ina são animais selvagens que se tornaram domesticados como plantas cultivadas”. Esta posição intermediária - para não dizer bastarda - não deixa de gerar certa contradição que, aliás, é muito bem ilustrada pela vigilância intensa à qual os xerimbabos são submetidos quando acompanham seu dono em antigas áreas de floresta derrubada. ${ }^{2}$ 
Quando desses deslocamentos pelas antigas roças, os Matis ficam realmente muito atentos a seus xerimbabos, cuidando, em particular, para que eles não provem de certos alimentos por vezes desenterrados; trata-se de raízes ou tubérculos (não identificados) cujos nomes indígenas são chombo, marun pwa, machicho, sësën dayo e dupamasho. De fato, tais comestíveis, descritos como "o que se comia antes da agricultura”, são muito pouco valorizados, mas seu consumo não é proibido aos bebês, nem, a fortiori, aos adultos. Por que tal proibição aos wiwa, senão em razão do paralelo facilmente estabelecido entre o estatuto ambíguo dos xerimbabos - tidos como crianças, ainda que vindas de alhures - e aquele, não menos paradoxal, dos vegetais cuja presença é apenas em parte imputável à ação direta do homem? Mesmo brotando em áreas preparadas para o plantio, eles não aparecem na lista bem definida de cultivares ordinários.

Para os Matis, as plantas encontradas numa área em via de reflorestamento representam certamente uma constatação do fracasso da domesticação, do retorno ao selvagem, que é incompatível com seu ideal de controle permanente sobre os espaços limpos. O próprio nome de uma das raízes incriminadas o comprova: literalmente, marun pwa, que significa "inhame de espírito maru”, este último encarnando a antítese dos valores matis. Compreende-se então porque os xerimbabos são mantidos à distância dos vegetais: o caráter "feral”, ou ao menos percebido como tal, destes últimos poderia se transferir metonimicamente aos wiwa que os consumissem, incitando-os a asselvajarem-se. Assim como as áreas de floresta derrubada, os animais familiares foram retirados da floresta e podem a ela retornar.

Os animais eram selvagens e tornaram-se familiares. As plantas eram domésticas e tornaram-se novamente selvagens. É plenamente compreensível que se faça o possível para evitar uma conjunção tão desconcertante. O seguinte esquema sintetiza os contrastes que se opõem na conjunção dos wiwa e das plantas "ferais":

\section{wiwa}

animal

não comestível

socializado

("cultura")

descendente

(pueril)

\section{plantas "ferais"}

vegetal

comestível

associal

("natureza")

ascendente

(ancestral) 
Se o contato com lugares e plantas "mal familiarizados" pode influenciar os wiwa, o inverso não é menos verdadeiro. É necessário então perceber a maneira como os Matis resolvem a dificuldade lógica ligada à inclusão de xerimbabos em seu espaço doméstico. De fato, uma "overdose" de presença animal seria sem dúvida arriscada no plano simbólico, e pode tornar-se um problema o número muito elevado de cativos humanos de origem estrangeira em uma dada sociedade. ${ }^{3}$ A antiga identidade, assim como os antigos donos sobrenaturais nunca estão muito longe...

A fim de justificar a presença perturbadora de seus corresidentes animais, os Matis recorrem a diferentes estratagemas, a maioria consistindo em humanizá-los (ou seja, desanimalizá-los). Em primeiro lugar, eles não usam mais para os xerimbabos o nome que designa normalmente seu ancestral de origem, preferindo empregar termos especiais que se ouvem com frequência, e duplicados, no vocativo (tabela 1). Os animais criados na aldeia são assim terminologicamente distintos da caça, sem dúvida com o objetivo de dissimular sua origem silvestre. ${ }^{4}$ Esta intenção fica clara, em particular, na transformação de kwëbu em shui, pois os dois termos são perfeitamente antinômicos: o primeiro evoca de forma clara o sexo feminino (kwë), enquanto o segundo é homônimo de pênis (shui). O xerimbabo pode ser caracterizado então como o contrapeso semântico da caça, simétrico e complementar, de acordo com um esquema extremamente difundido na Amazônia (Erikson, 1987). Tanto é assim que, para chamar as galinhas, contenta-se em utilizar seu nome específico, takara, apenas redobrado (takara, takara), pois não há razão alguma para camuflar a origem destes animais, desprovidos de contrapartida silvestre.

A lista a seguir inclui todos os xerimbabos que pude observar em minha estada entre os Matis. Ela não tem, entretanto, nenhuma pretensão de exaustividade. Nela não estão, em particular, o caititu unkin (Tayassu tajacu), e o macaco bugio du (Alouatta sp.), para os quais nos faltam dados. 


\begin{tabular}{|c|c|c|}
\hline Espécie & Nome vernacular & Vocativo \\
\hline \multicolumn{3}{|l|}{ Macacos : } \\
\hline Sagui (Saguinus sp.) & sipi chot & ishpi ishpi \\
\hline $\begin{array}{l}\text { Sagui-de-mãos-amarelas } \\
\text { (Mydas sp.) }\end{array}$ & sipi wiren & ishpi ishpi \\
\hline $\begin{array}{l}\text { Titi-vermelho } \\
\text { (Callicebus cupreus) }\end{array}$ & masoko & seri seri \\
\hline Macaco-barrigudo (Lagotrix sp.) & chuna & poshtu poshtu \\
\hline Macaco-aranha (Ateles sp.) & choshe & musha musha \\
\hline Macaco-de-cheiro (Saimiri sp.) & tsama & tsanga tsanga \\
\hline Macaco-da-noite (Aotus sp.) & bushti & bushigi bushigi \\
\hline Macaco-prego (Cebus sp.) & chima & ishpa ishpa \\
\hline Macaco-parauacu (Pithecia sp.) & bushiro & $\begin{array}{l}\text { manan mamut } \\
\text { manan mamut }\end{array}$ \\
\hline \multicolumn{3}{|l|}{ Diversos mamíferos: } \\
\hline Cachorros (Canis sp.) & wapa & kuri kuri \\
\hline Queixada (Tayassu albirostris) & chawa & pusa pusa \\
\hline $\begin{array}{l}\text { Preguiça } \\
\text { (Bradypus \& Choelus spp.) }\end{array}$ & pusin & nai nai \\
\hline Quati (Nasua sp.) & sise & kashta kashta \\
\hline \multicolumn{3}{|l|}{ Pássaros: } \\
\hline Jacutinga (Pipile sp.) & niwa & titan titan \\
\hline Jacu (Penelope sp.) & kwëbu & shui shui \\
\hline Mutum (Crax sp.) & wesnit & kushti kushti \\
\hline Tucano (Ramphastos sp.) & chankwish & shuku shuku \\
\hline
\end{tabular}

Tabela 1: nomeação dos xerimbabos

Outras precauções são tomadas para negar a animalidade dos xerimbabos e atribuir-lhes estatuto comparável ao das crianças. Além de modificar sua designação específica, são dados a eles nomes pessoais de humanos (jamais usados, mas capazes de inseri-los numa parentela); eles são por vezes enfeitados com miçangas, levados nos braços e, sobretudo, são enterrados após a morte, evitando-se tratá-los como seus congêneres destinados à panela. É, portanto, extremamente mal visto bater num animal familiarizado (ao passo que a caça pode 
ser maltratada), é proibido, mesmo após sua morte, retirar dentes de macacos familiarizados (ainda que os colares feitos com esses dentes sejam o bem mais valioso entre os Matis). Enfim, e acima de tudo, é proibido consumir sua carne. ${ }^{5}$

São, porém, as práticas ligadas à sua alimentação que contribuem de modo mais eficaz para a socialização dos xerimbabos. A comensalidade é, em toda a Amazônia, um critério essencial de humanização dos animais (Erikson, n.d.). Ainda que os Matis evidentemente saibam, por exemplo, que os pequenos macacos coletam insetos e que os caititus forrageiam aqui e ali, eles concedem muita importância à ideia de que seus wiwa recebem uma alimentação cultural. Os mamíferos são alimentados no seio e depois, como os pássaros e os bebês humanos, recebem alimentos pré-mastigados oferecidos boca a boca. Considerados e mimados como crianças, supõe-se que os xerimbabos se alimentem da mesma maneira, de modo que a coprofagia dos cães é particularmente mal vista.

Os Matis discutem livremente as preferências gastronômicas de seus animais, afirmando que tal variedade de banana convém melhor a tal espécie de macaco etc. Um jovem homem, interrogado sobre a dieta dos xerimbabos, chegou até a nos dizer que certas espécies não hesitavam em comer a carne dos parentes dele. O sorriso eloquente acompanhando essas palavras traduziria certamente a ironia da situação, mas também a satisfação real que tal prova de renúncia à sua própria espécie parecia lhe trazer. Alimentando os onívoros com seus próprios congêneres, os Matis contribuem evidentemente para humanizá-los.

Constata-se, aliás, que o alimento cultivado que mais convém a um xerimbabo é aquele que será mais facilmente consumido para acompanhar a carne de seus congêneres: se os homens foram caçar macacos com suas zarabatanas, as mulheres tratam de cozinhar bananas antes de seu retorno; se eles perseguem caititus, elas vão recolher mandioca. O que é bom para um animal é igualmente bom como acompanhamento de sua carne...

Assim, os animais familiarizados apenas têm lugar no espaço humano na medida em que são assimilados. Não podendo ser considerados hóspedes, eles permanecem ali enquanto membros naturalizados, ao contrário dos animais privados de acesso à casa, e cujo ponto comum é justamente o fato de não se beneficiarem de nenhuma ligação interpessoal humanizante com um dono: seja no caso em que eles acabam de ser capturados, e se encontram então em quarentena ou em trânsito nos abrigos periféricos construídos para tal fim, seja quando pertencem a espécies recentemente introduzidas (galinhas, patos) e, portanto, excluídas do processo de familiarização. Em todos estes casos, os animais em questão não têm ainda (ou não terão jamais) o "estatuto social” requerido para penetrar no shobo. A racionalização segundo a qual as galinhas são demasiado barulhentas e vorazes para coabitar com os humanos ou para aproximar-se do 
telhado não enganará nenhum daqueles que já foram vítimas dos jacus insones ou dos micos abusados que, apesar disso, podem habitar a casa comum.

Uma vez considerados xerimbabos plenos, os animais familiares tornam-se quase um prolongamento do corpo de seu proprietário, tendo, assim, acesso ao menor recanto da habitação. Constata-se, portanto, que os wiwa são atribuídos a indivíduos, mais do que a locais; são hóspedes do homem mais que de sua casa, o que torna particularmente delicado um estudo "topológico" de sua ocupação do espaço. Seria ilógico, uma vez um animal familiarizado, confiná-lo em um local específico, e ao mesmo tempo buscar negar a sua especificidade. Os poleiros, os abrigos e outros recintos representam apenas soluções provisórias, destinadas a desaparecer tão logo a assimilação se realize.

Sobre isso, o caso dos cachorros é particularmente interessante. Em tempos passados, estes companheiros mais recentes do homem, assim como as galinhas, estavam destinados a residir na periferia, presos em recintos. No presente, suas proezas cinegéticas lhes valeram não apenas a entrada na casa comum, como também o direito de assento no círculo central, onde os homens fazem suas refeições em conjunto. Aqui, é a filogênese acelerada que reproduz a ontogênese, mais do que o inverso, pois os cachorros foram, enquanto espécie, pouco a pouco integrados na casa, da mesma forma como os animais capturados na floresta o são individualmente.

Assim que possível, portanto, o xerimbabo deixa de ser mantido em separado para ficar próximo de seu dono. Raramente um animal é deixado só, exceto os mais volumosos. Se alguém está cansado da presença de seu macaco sobre a cabeça, ele o repassa a uma criança, recomendando-lhe que o coloque na de um parente, sem deixá-lo solto. Idealmente, o xerimbabo vai onde está seu dono: eles dormem em suas redes (ao menos os macacos), vão se banhar com eles, ${ }^{6}$ acompanham-nos à roça e inclusive à caça, sobretudo no caso dos cachorros e dos pequenos macacos empregados como iscas naturais. A regra segundo a qual os animais devem seguir os humanos em seus deslocamentos é, aliás, explícita: é recomendado, ou mesmo obrigatório, levá-los por toda parte. Diz-se que os animais devem kapwek, deslocar-se na floresta, como os humanos. Ora, para se compreenderem as limitações que isso pode acarretar, basta observar a dificuldade com que se movimenta a mais velha das macho (sobrenome dado às mulheres na menopausa) matis. Apesar de sua excelente condição física, ela geralmente só pode avançar mancando ou através de saltitos: mas, afinal, como fazer de outro modo com um enorme macaco-aranha agarrado à panturrilha e um caititu caprichoso sempre atrás? ...

Para compreender a inserção dos animais no espaço matis, é necessário, portanto, demorar-se um pouco sobre as regras que presidem sua repartição entre os diversos indivíduos. 


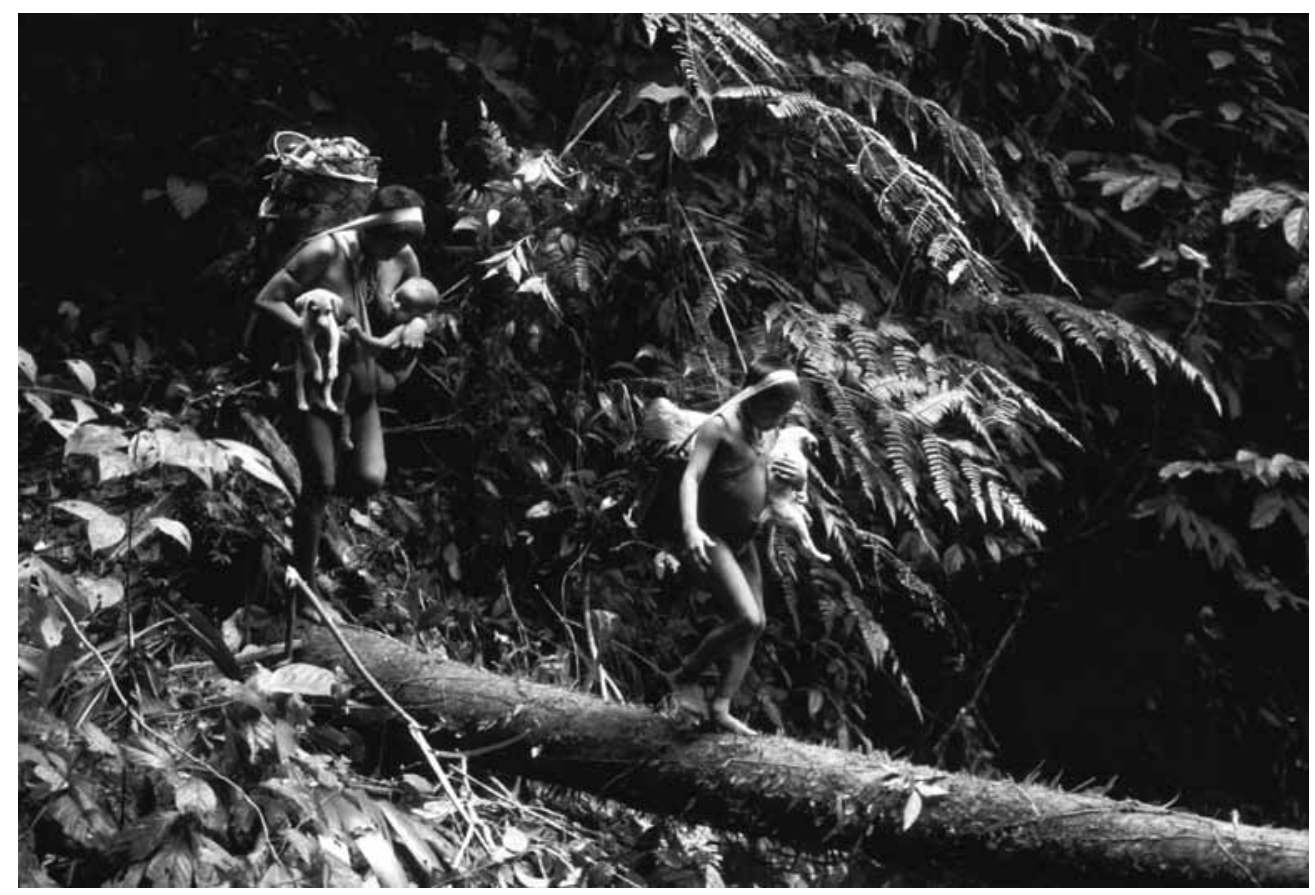

1: Nas expedições, os animais estão sempre junto... (Col. Erikson, 1995)

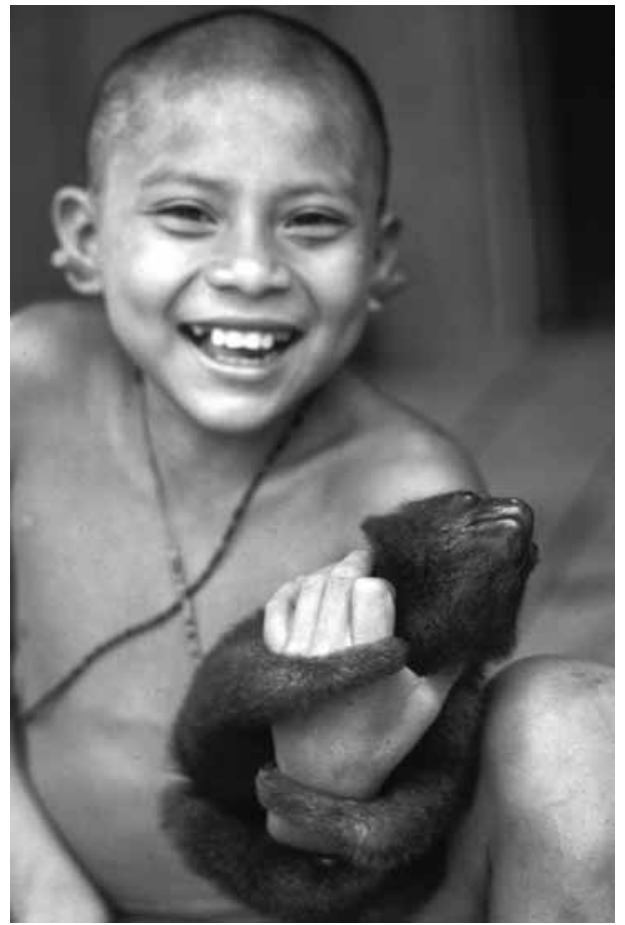

2: Mena e sua preguiça doméstica. (Col. Erikson, 1995) 


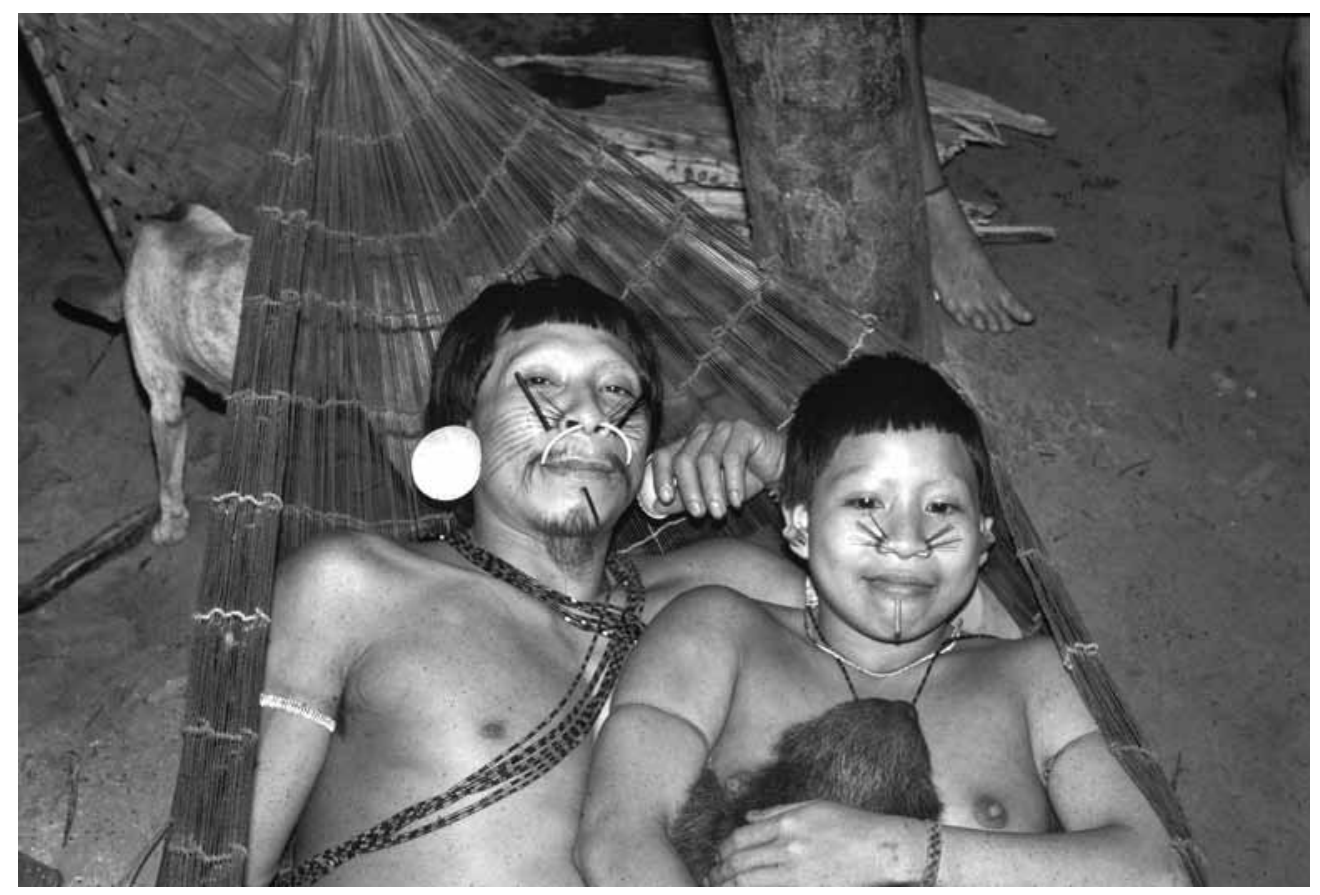

3: Binã shono, Kana e sua preguiça doméstica. (Col. Erikson, 1995)

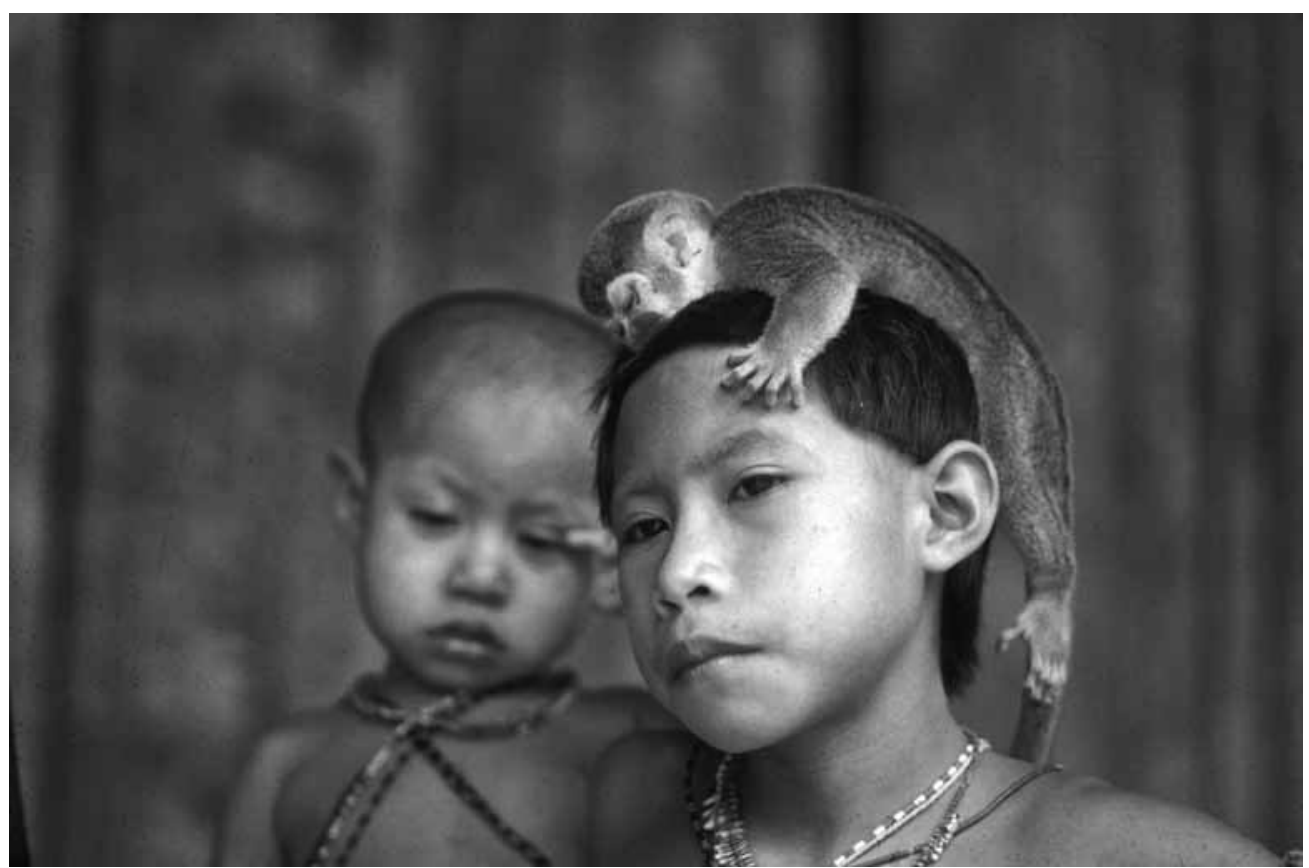

4: Os macacos são sempre levados sobre a cabeça. (Col. Erikson, 1995) 
Ainda que os animais familiares sejam comumente jovens trazidos da caça pelos homens, são geralmente as mulheres e as crianças que desfrutam da propriedade formal dos xerimbabos. Evidentemente, sua repartição não se efetua ao azar, e tampouco sem lembrar a divisão da carne: os homens os oferecem sobretudo a suas esposas, suas amantes e suas mães, por vezes a seus filhos. Individualmente falando, a possibilidade de alguém se recusar a criar um animal trazido da caça sempre existe. Para uma jovem solteira, por exemplo, aceitar um jovem caititu equivaleria a tomar um encargo suplementar, e praticamente a se engajar na criação dos filhos do caçador que o ofereceu. É o caso, portanto, de refletir bem antes de aceitar. ${ }^{7}$ Mas para a maior parte das outras mulheres, a chegada de um novo animal de companhia consiste em um acontecimento dos mais agradáveis. O xerimbabo servirá de brinquedo para as meninas, de laboratório de etologia para os meninos, de substituto de filho para as mulheres velhas ou estéreis (particularmente predispostas ao processo de familiarização), de divertimento para todos.

A partilha dos animais depende então largamente da situação familiar de cada um. Constata-se, aliás, uma forte tendência à repartição específica dos animais, parecendo que os diferentes tipos de xerimbabos estão relacionados com as diversas etapas do ciclo vital. Isto fica particularmente claro em se tratando de macacos, cujas espécies menores são com frequência atribuídas às crianças, as médias aos jovens adultos, e assim por diante, até o macaco-aranha negro (esta cor conotando a maturidade), reputado por sua inteligência, em geral reservado aos anciãos. Assim, observa-se um mico ou um sagui sobre a cabeça dos bebês, enquanto os titis, um pouco maiores, são característicos das mães muito jovens e das esposas novas, os caraí estando, por sua vez, se não reservados, ao menos preferencialmente ofertados a pessoas de meia-idade. Os macacos-barrigudos, enfim, talvez em razão de seu ventre inchado, que evoca o das grávidas e o dos bebês, costumam ser confiados às mulheres que há tempos não têm filhos.

Principal corolário desse paralelo entre a faixa etária do proprietário e a dimensão do xerimbabo: a repartição espacial dos animais segue a dos humanos e, via de regra, os pequenos animais brincam sobretudo no rio, enquanto os maiores dirigem-se mais à roça. Em todos os casos, o lugar dos animais decorre mecanicamente daquele de seu dono, de maneira que é difícil associá-los a um ponto fixo, a não ser a própria pessoa que faz as vezes de seu vetor humano.

Concluindo, não podemos senão reafirmar o paradoxo matis: os animais não tendo e não podendo ter lugar algum na casa dos homens, na verdade estão por todos os lados, sendo, desde que são ali admitidos, considerados como membros plenos da comunidade. Pode-se, em suma, pensar que o seu espaço topográfico 
deriva logicamente do "lugar" que eles ocupam no seio de um sistema de valores no qual a questão do espaço (humano ou animal) constitui um grande desafio.

Recebido em 22/10/2012

Aceito em 29/10/2012

Philippe Erikson é professor na Université Paris Ouest Nanterre, e membro do Laboratoire d'Ethnologie et de Sociologie Comparative (Lesc, umr 7186). Especialista na família etnolinguística pano, pesquisou longamente entre os Matis da Amazônia brasileira (20 meses entre 1984 e 2006) e os Chacobo da Amazônia boliviana (23 meses entre 1991 e 2011). Em 2007, ele esteve também brevemente entre os Cashinahua, do lado peruano da fronteira. Além da relação homem-animal, seus trabalhos abordam essencialmente a organização social, as relações entre o simbolismo e a cultura material, as mascaradas rituais, as tatuagens, a ornamentação corporal e a construção de identidades coletivas nas terras baixas da América do Sul. 


\section{Notas}

1. De todos os animais caçados com frequência, apenas a anta (Tapirus terrestris) nunca é criada. Esta única exceção provém antes do perigo sobrenatural que ela representa do que das dificuldades reais, suplantáveis, relativas à sua familiarização (Frank, 1987). Tradicionalmente, nenhum dos animais dos Matis é, propriamente falando, domesticado, pois sua reprodução se efetua apenas excepcionalmente em cativeiro. Acontece por vezes, segundo os Matis, que macacos nasçam na aldeia, mas, contrariamente a Serpwell (1988), parece-nos difícil ver nisso um primeiro passo em direção à domesticação. Por um lado, em razão da raridade extrema deste fenômeno (agravado pela taxa de sobrevivência e a longevidade derrisórias dos xerimbabos); de outro lado, por razões ideológicas esboçadas em Erikson (1987, 2000), que diferem consideravelmente daquelas avançadas por Descola (1998a). Este defende, na verdade, a posição hiperculturalista, segundo a qual os animais não teriam sido domesticados na Amazônia porque eles já assim estavam no imaginário. Para uma refutação desta posição, ver Erikson (1998), que leva em consideração o aspecto etnozootécnico da questão e amplia a reflexão, incluindo a introdução de animais domésticos de origem europeia. Para explicações mais utilitaristas sobre a ausência de domesticação na Amazônia, ver Gade (1985, 1987).

2. Como a maior parte das populações amazônicas, os Matis praticam uma policultura itinerante com o uso de queimadas, abrindo novas roças regularmente. Isto dito, ainda que as antigas roças sejam deixadas após dois ou três anos de produção, elas jamais são completamente abandonadas, as pessoas as revisitam periodicamente para caçar e, sobretudo, para recolher cachos de pupunha (wani; Guilielma gasipaës).

3. Santos-Granero (2009) evoca alguns exemplos deste tipo. Na mesma direção, um Marubo contou-me certa vez que seus parentes, capturados outrora pelos Matses, ainda que perfeitamente integrados, teriam sido por fim mortos. Na verdade, eles se tornaram tão numerosos que conseguiram fundar sua própria maloca, em prejuízo de seus raptores.

4. Os Wayãpi (ameríndios de língua tupi) recorrem a estratagema idêntico, camuflando a origem silvestre de seus animais familiares ao modificarem seus nomes (Grenand, 1980). Entre os Matis, a maior parte dos termos novos não tem, até onde posso saber, nenhuma significação específica, à exceção de poshto ("ventre”) e musha ("espinho"). Alguns se encontram no léxico dos grupos Pano vizinhos, como designação "ordinária” de uma espécie. Dienst e Fleck (2009), primeiros a chamar a atenção dos linguistas sobre este fenômeno, propuseram designar tais termos de "pet vocatives".

5. A maioria dos ameríndios das terras baixas da América tropical proíbe totalmente o consumo de animais familiarizados (Erikson, n.d.). Contrariamente à maioria dos outros povos amazônicos (mas assim como os Tupis de Rondonia [Dal Poz, 1993] e outros membros de sua família linguística, tal como os Shipibo [Roe, 1982] ou os Cashibo [Frank, 
1987]), os Matis praticam um ritual no qual um animal familiar é morto e comido depois que os consumidores tenham sofrido flagelações rituais, como se para expiar tal transgressão. Isto posto, o consumo de xerimbabos fora desse contexto muito particular é objeto de absoluta proibição. Cabe notar que isso é particularmente estrito no caso dos adolescentes (buntak), que não podem em hipótese alguma consumir carne de animais familiarizados, sem dúvida porque uma das condições necessárias para a suspensão da proibição desta carne é suportar chicotadas rituais. Ora, em tempos ordinários (mesmo fora do ritual de morte de um xerimbabo), os buntak são precisamente os principais receptáculos das flagelações rituais, destinadas a fortalecê-los e a fazê-los crescer. O chicote é, portanto, "normal" entre eles, e não poderia ser assim excepcional...

6. Note-se, entretanto, que algumas espécies (macacos barrigudos e titi-vermelhos, especialmente) são proibidas de ter contato com a água. Os Matis dizem que elas não suportam nem banho, nem chuva.

7. Teoricamente, é proibido aos jovens adolescentes (buntak) criar animais. Aceitar a oferta de um caititu - assim como assistir a um parto - equivale a reconhecer uma mudança de estatuto. Inclusive, parece que toda a lógica simbólica matis visa afastar sistematicamente os adolescentes humanos dos animais familiares, sem dúvida em razão da natureza simétrica e inversa de suas respectivas trajetórias (descendente para os animais, ascendente para os jovens). De fato, os xerimbabos, que jamais apanham, são de alguma maneira uma via de juventude, pois o objetivo da familiarização é justamente o de fazer “crianças", enquanto os adolescentes, ao contrário, são precisamente açoitados para que amadureçam. Ou seja, uns como os outros estão em categorias que se poderia definir como "transitórias", assegurando a passagem do doméstico ao selvagem, num caso; do imaturo ao maduro, no outro. Sem dúvida, é igualmente em função dessa propensão a encarnar a liminaridade de maneira quase icônica que os buntak são igualmente aqueles a quem se deve obrigatoriamente confiar o preparo ritual da primeira presa da metade ayakobo abatida com uma zarabatana nova, que até então tenha servido apenas para matar presas da metade tsasibo (Erikson, 2001). Com efeito, ao final dessa refeição ritual, a zarabatana passa do status de uma arma jovem, destinada a matar "animais próximos" (tsasibo), ao de uma arma madura, usada para matar animais "distantes" (ayakobo). 


\section{Referências bibliográficas}

BEHRENS, Clifford. 1983. Shipibo Ecology and Economy. Ph.D. dissertation, University of California, Los Angeles, University Microfilms International, Ann Arbor.

CALAVIA SAEZ, Oscar. 2010. "O melhor parente do homem". Disponível em: http:// www.revistadehistoria.com.br/secao/capa/o-melhor-parente-do-homem. Acessado em: 21/04/2012.

CORMIER, Loreta. 2003a. "Animism, cannibalism, and pet-keeping among the Guajá of Eastern Amazonia”. Tipiti, v. 1, n.1:81-98.

. 2003b. Kinship with monkeys. The Guajá foragers of eastern Amazonia. New York:

Columbia University Press.

CREVAUX, Jules. 1987 [1879]. Le mendiant de l'Eldorado. De Cayenne aux Andes, 1876-1879. Paris: Phébus.

DAL POZ, João. 1993. "Homens, animais e inimigos: simetrias entre mito e rito nos Cinta Larga”. Revista de Antropologia, São Paulo, USP, v. 36:177-206.

DESCOLA, Philippe. 1998a. "Pourquoi les indiens d'Amazonie n’ont-ils pas domestiqué le pécari? Généalogie des objets et anthropologie de l'objectivation”. In: Lemonnier \& Bruno Latour (eds.). De la préhistoire aux missiles balistiques. L'intelligence sociale des techniques. Paris: Editions de la Découverte. pp. 329-244.

. 1998b. "Estrutura ou sentimento: A relação com o animal na Amazônia”. Mana, n. $4(1): 23-45$.

DIENST, Stefan \& FLECK, David W. 2009. "Pet vocatives in Southwestern Amazonia". Anthropological Linguistics, 51 (3-4):209-243.

ERIKSON, Philippe. n.d. [1983]. "L'animal (sauvage, familier, domestique) en Amazonie indigène”. Mémoire de maîtrise, Université Paris X-Nanterre.

. 1987. "De l'apprivoisement à l'approvisionnement. Chasse, alliance et familiarisation en Amazonie amérindienne”. Techniques et Cultures, 9:105-140.

. 1988. "Apprivoisement et Habitat chez les Amérindiens Matis (Langue Pano, Amazonas, Brésil)”. Anthropozoologica, n. 9:25-35.

. 1998. "Du pécari au manioc ou du riz sans porc ? Réflexions sur l'introduction de la riziculture et de l'élevage chez les Chacobo (Amazonie bolivienne)". In: Martine Garrigues-Cresswell \& Marie Alexandrine Martin (eds.). Résistance et changements des comportements alimentaires. Techniques \& culture, nº spécial 31-32:363-378. 
2000. "The Social Significance of Pet-keeping among Amazonian Indians". In:

Paul Poberseck \& James Serpell (eds.). Companion Animals and Us. Cambridge: Cambridge University Press. pp. 7-26.

2001. "Myth and Material Culture: Matis Blowguns, Palm Trees, and Ancestor Spirits". In: Laura Rival \& Neil Whitehead (eds.). Beyond the Visible and the Material: the Amerindianization of Society in the Work of Peter Rivière. Oxford: Oxford University Press. pp. 101-121.

FAUSTO, Carlos. 2008. "Donos demais: maestria e propriedade na Amazônia". Mana 14:280-324.

FRANK, Erwin. 1987. “Die Tapirfest die Uni”. Anthropos, 82:151-181.

GADE, D.W. 1985. "Animal/man Relationships of Neotropical Vertabrate Fauna in Amazonia”. Nat. Geogr. Soc. Res. Rep., 18:321-326.

(ed.). 1987. "Festschrift to Honor Frederick J. Simoons". Journal of Cultural Geography, nº́cial, 7(2).

GRENAND, Pierre. 1980. Introduction à l'étude de l'Univers Wayãpi. Ethnoécologie des Indiens du Haut Oyapock, Guyane Française. Paris: SELAF.

KOSTER, Jeremy. 2009. "Hunting Dogs in the Lowland Neotropics". Journal of Anthropological Research, v. 65:575-610.

ROE, Peter. 1982. The Cosmic Zygote. New Brunswick, New Jersey: Rutgers University Press.

SANTOS GRANERO, Fernando. 2009. Vital Enemies. Slavery, Predation, and the Amerindian Political Economy of Life. Austin: Texas University Press.

SERPELL, James. 1988. In the Company of Animals: A study of Human-Animal Relationships. New-York: Cambridge University Press.

TEXEIRA PINTO, Márnio. 1997. Ieipari. Sacrifício e vida social entre os índios Arara. São Paulo: Editora Hucitec/Anpocs/Editora ufpr.

VANDER VELDEN, Felipe. 2010. Inquietas Companhias: sobre os animais de companhia entre os Karitiana. Tese de Doutorado em Antropologia Social, Universidade de Campinas.

. 2011. "Rebanhos em aldeias: investigando a introdução de animais domesticados e formas de criação animal em povos indígenas na Amazônia (Rondônia)”. Espaço Ameríndio, Porto Alegre, v. 5, n. 1:129-158.

VILLAR, Diego. 2005. "Indios, blancos y perros". Anthropos (Sankt Augustin), 100 (2):495-506. 


\section{Resumo}

Para os Matis, o espaço obtido da floresta para habitar e cultivar representa uma conquista sobre o universo dos animais e dos espíritos, um espaço socializado que deve ser preservado a todo custo contra o possível retorno dos antigos donos. Por isso, os animais familiares admitidos na maloca formam, enquanto categoria liminar, na fronteira entre o social e o anti-social, um perigo simbólico que pode ser comparado aos trechos de florestas em processo de regeneração. As restrições topográficas impostas aos animais familiares refletem portanto a ambiguidade inerente à sua inserção social.

Palavras-chave: Amazônia, Matis, povos indígenas, animais familiares, espíritos-donos

\section{Abstract}

For the Matis, human dwelling space and areas used for slash-and-burn agriculture are but temporary clearings in the jungle and as such, ground gained against its original inhabitants. Great care is therefore taken to protect this socialized space against possible recapture by its pristine owners: animals and forest-dwelling spirit beings. Pet animals, as a liminal category on the threshold between social and anti-social, therefore appear as symbolically dangerous, in many ways like fallow gardens on their way towards forest regeneration. The topographical restrictions imposed on pets therefore reflect the inherent ambiguity and frailty of their social integration.

Keywords: Amazon, Matis, indigenous people, pets, masters spirits 